\title{
A FUZZY KNOWLEDGE-BASED FRAMEWORK FOR RISK ASSESSMENT OF RESIDENTIAL REAL ESTATE INVESTMENTS
}

\author{
Mónica I. F. RIBEIROa ${ }^{\mathrm{a}}$, Fernando A. F. FERREIRA ${ }^{\mathrm{b}}$, \\ Marjan S. JALALIc ${ }^{\mathrm{c}}$, Ieva MEIDUTE்-KAVALIAUSKIENE ${ }^{\mathrm{d}}$ \\ ${ }^{a}$ School of Management and Technology, Polytechnic Institute of Santarém, Complexo Andaluz, \\ Apartado 295, 2001-904 Santarém, Portugal \\ ${ }^{b}$ ISCTE Business School, BRU-IUL, University Institute of Lisbon, Avenida das Forças Armadas, \\ 1649-026 Lisbon, Portugal \\ ${ }^{b}$ Fogelman College of Business and Economics, University of Memphis, Memphis, TN 38152-3120, USA \\ 'ISCTE Business School, BRU-IUL, University Institute of Lisbon, \\ Avenida das Forças Armadas, 1649-026 Lisbon, Portugal \\ ${ }^{d}$ Faculty of Business Management, Vilnius Gediminas Technical University, \\ Sauletekio al. 11, LT-10223 Vilnius, Lithuania \\ ${ }^{d} B R U-I U L$, University Institute of Lisbon, Avenida das Forças Armadas, \\ 1649-026 Lisbon, Portugal
}

Received 07 October 2014; accepted 03 November 2015

\begin{abstract}
Risk analysis of residential real estate investments requires careful analysis of certain variables (or determinants). Because real estate is a key sector for economic and social development, this risk analysis is seen as critical in supporting decision processes relating to buying or selling residential properties, partly due to the pressures caused by the current economic environment. This study aims to develop a conceptual reference model for risk assessment of residential real estate using fuzzy cognitive mapping. This fuzzy model allows cause-and-effect relationships between determinants to be identified and better understood, which in turn allows for better informed investment decisions. The results show that the use of cognitive maps reduces the number of omitted criteria and favors learning with regard to how the criteria relate to each other, holding great potential and versatility in structuring complex decision problems. Practical implications, strengths and weaknesses of our proposal are discussed.
\end{abstract}

Keywords: decision making, risk analysis of real estate investments, residential real estate, fuzzy cognitive maps.

JEL Classification: C44, C45, M10, R31.

Corresponding author Fernando A. F. Ferreira

E-mails: fernando.alberto.ferreira@iscte.pt; fernando.ferreira@memphis.edu 


\section{Introduction}

Risk analysis of real estate investments is simultaneously one of the most important and undervalued areas of finance. The uncertainty of the current economic climate, however, motivated initially by the subprime crisis and, more recently, by the sovereign debt crisis, has been asserting itself as a determining factor in how the financial sector analyzes the housing segment. Changes in the real estate market have a significant impact on other sectors of economic activity and, therefore, on the well-being of the society at large. Ebru and Eban (2009), Kauko (2010), Rybak and Shapoval (2011) and Warren (2011), among others, argue that the real estate market, namely the housing segment, is crucial for economic development. This idea is further reinforced by Syz et al. (2008) and Rybak and Shapoval (2011), who point to the relevance of this market for national wealth. Yet despite the growing importance that has been given to risk analysis of residential real estate investments, this field of research is still relatively unexplored, an issue that is reinforced by the effects of the current global economic crisis. As a result, there is considerable scope for new methodological approaches to support decision-making processes and allow for better informed, more transparent and robust investment decisions.

Starting from the premise that the use of fuzzy cognitive mapping techniques fosters an understanding of how the determinants of investment risk relate to each other, this study aims to contribute to the development of a decision-making framework for risk analysis of residential real estate investments. Specifically, by constructing a fuzzy cognitive map (FCM), our framework aims to: (1) identify the determinants of the risk of investment in residential real estate; (2) contribute to reduce the number of omitted criteria in the decision making process; and (3) increase our understanding of how the determinants of risk analysis in the context of this study relate to each other. In this sense, it is worth noting that, according to Carlucci et al. (2013: 208), "FCM is a well-established artificial intelligence technique, incorporating ideas from artificial neural networks and fuzzy logic, which can be effectively applied in the domain of management science".

The remainder of this paper is structured as follows. The next section provides the literature review on risk assessment of residential real estate investments. The ensuing section presents the methodological background, justifying the use of FCMs in the context of this study. The following section describes the process followed for the construction of our FCM, and discusses the major advantages and shortcomings of our methodological proposal. The last section presents concluding remarks and some lines for future research.

\section{Risk assessment of real estate investments and related work}

Owning a house is the largest single investment most households will make; and at the same time, in most cases, it is limited by severe budget restrictions. In such circumstances, bank loans become the most common and, perhaps, easiest practice for house acquisition (Ferreira et al. 2013a). From an economic development standpoint, it is worth noting that, due to the current economic instability (which affects the real estate market, reducing the purchasing power of households and, consequently, motivating falls in private consump- 
tion, housing included), financial institutions have become more demanding in approving loan applications and, as a result, have reduced lending concessions by imposing higher credit underwriting standards to compensate the risk they face (cf. Ferreira et al. 2013a).

In practice, the real estate market has presented a generalized oversupply over the last two decades ( $c f$. Catalão 2010) and, due to the current economic climate, it is particularly directed at those who have capital available to invest. For those who do not, bank loans have been the solution. Thus, it seems clear that financial institutions help support investment in this sector, and that without the support of banks it would not be possible for families to invest in real estate. It is in this sense that bank loans stimulate the economy of a country; i.e. they encourage property acquisition by householders, strengthening the construction sector and, consequently, increasing employment, money circulation and GDP growth (for further discussion, see Ferreira et al. 2013a).

Real estate investments are generally considered high risk. Not only do they typically involve significant amounts of money, but the investor is negotiating an asset that is expected to be profitable in the long term. This type of business is also risky for the financial institutions which fund the investment and, naturally, require a thorough evaluation of loan applications. This, in turn, requires taking into account the house value, the amount required and the duration of the lending contract. According to Tavares et al. (2009), real estate appraisal is an activity that depends on many factors, and should be conducted by those who operate in the field and possess a broad range of knowledge about prices, construction costs, urbanism, supply-demand behavior, as well as about market trends and fluctuations.

Given the increased risk of default, risk analysis is thus paramount for the housing market. It is worth noting, however, that 'emerging markets' real estate performance is nowadays heavily affected by lack of investor confidence, risk perceptions, increasing cost of finance and finally market fundamentals" (Onofrei, Anghel 2012: 481). In this sense, risk evaluation of real estate investments needs to be as complete as possible. As pointed out by Yancang and Juanjuan (2009: 138), "the risk evaluation of the real estate is more and more important. But, how to find an effective method to determine the weight of every risk factor and how to deal with the uncertainty of the evaluation are urgent questions. Lots of efforts have been done. But, we still have a long way to go". This premise is further supported by Wenpo and Minli (2012: 1815), who argue that "real estate investment is a high-risk [...] activity, the key of real estate analysis is the identification of their types of investment risk and the risk of different types of effective prevention". This means that it is important to identify both the risks associated with investing in real estate but also to achieve effective solutions that allow appraisals to be improved. Following this, and according to Doumpos and Zopounidis (2001: 98), "while several multivariate statistical and econometric analysis techniques (e.g. discriminant analysis, logit and probit analysis, the linear probability model, etc.) have been used to address this type of problems, their methodological shortcomings have already led researchers towards the exploitation of new operational approaches". Indeed, as noticed by Šušteršic et al. (2009: 4736), the classic parametric approaches (e.g. linear discriminant analysis, linear regression, logit, probit, tobit and binary tree) "are reported to have a lack of accuracy [in this field]". In addition, the current approaches for residential real estate risk evaluation are usually limited by: (1) lack of necessary data (Lopez, Saidenberg 2000); (2) lack of rationality in the way trade-offs between criteria 
are calculated (Ferreira et al. 2012); and (3) the need to make subjectivity explicit in the decision making process (Santos et al. 2002) (for further discussion, see also Wang et al. 2011).

In light of these limitations, there seems to be considerable scope to explore the applicability of fuzzy cognitive mapping techniques in the context of risk analysis of residential real estate investments. Although several fuzzy risk evaluation models for real estate investments exist in the literature (e.g. Wenpo, Minli 2012), it is worth noting that cognitive mapping not only enables a large number of determinants to be identified, but it increases transparency in the sense that it is clear where the data is coming from (Ackermann, Eden 2001; Ferreira, Jalali 2015). In addition, with FCMs, the relative importance of the criteria is calculated according to the experts' own perceptions of that importance and after discussion and negotiation among the panel members, whereby subjectivity is not only made explicit, but it is incorporated and turned into a strength of the process.

Because FCMs are grounded on the practical experience, technical skills and realism brought by the decision makers, they can potentially be used by parties investing in real estate. The proposal presented here is constructivist in nature (see Ferreira et al. 2014), and offers a perspective of complementarity rather than substitution. The next section presents the methodological background of our proposal and explores the applicability of the fuzzy cognitive mapping approach in the context of this study.

\section{Methodological background}

Steiger, D. and Steiger, N. (2008: 313) defend that "mental models are tacit, hypothetical knowledge structures that integrate the ideas, practices, assumptions, beliefs, relationships, insights, facts and misconceptions that together shape the way an individual views and interacts with reality". Decision aids based on human cognition can thus be seen as an opportunity for problem structuring because, according to Keeney (1996), "decision makers usually think of decision situations as problems to be solved, not as opportunities to be taken advantage of". Cognitive maps become useful in decision making processes, because they can help identify opportunities of action, reduce errors and search for good solutions ( $c f$. Ferreira et al. 2012). In practice, these maps are tools for structuring complex problems; and as such, they contribute to reduce the rate of omitted criteria, promote discussion, and lead to increased learning among the actors involved in the decision making framework, as a result of the exchange of ideas and experiences ( $c f$. Tegarden, Sheetz 2003; Eden, Ackermann 2004; Jalali et al. 2016).

Carlucci et al. (2013) and Ferreira et al. (2016), among others, note that cognitive maps have two main functions: (1) a descriptive function, i.e. they provide visual representations, helping individuals to have a better perception of the problem at hand, thus facilitating its resolution; and (2) a function of reflection, in which the map is seen as a tool to support the development of new ideas. In practical terms, a cognitive map consists of a network of ideas, hierarchically structured and connected by arrows, whose direction indicates the cause-andeffect relationship between criteria ( $c f$. Eden 2004; Eden, Ackermann 2004). In addition, the arrows can have positive (+) or negative (-) signs, depending on the type of cause-andeffect relationship between the existing concepts ( $c f$. Montibeller, Belton 2006; Ferreira et al. 
2012). In short, cognitive maps are presented as representations of the environment; provide a snapshot of reality and allow the understanding of cause-and-effect relationships between concepts or variables to be clarified.

\subsection{Fuzzy cognitive maps}

The concept of FCM was introduced by Kosko (1986), who combined cognitive maps with fuzzy logics. As pointed out by Carlucci et al. (2013: 212), "Kosko enhanced the power of cognitive maps considering fuzzy values for the concepts of the cognitive map and fuzzy degrees of interrelationships between concepts". Fuzzy logics was developed in the 1960s and has been widely used to model social, economic and political problems (cf. Carvalho 2013). It is an approach that holds great potential in dealing with investment decisions in residential real estate, namely because it helps to understand and analyze the associated risk.

FCMs have two particular characteristics: (1) the cause-and-effect relationships $W_{i j}$ between concepts/criteria $C_{i}$ and $C_{j}$ follow a fuzzy logic; and (2) the system is dynamic, i.e. it involves feedback links between criteria (Fig. 1).

In addition to the graphical representation, FCMs have a mathematical basis. According to Kok (2009), Mazlack (2009), Carlucci et al. (2013) and Ferreira and Jalali (2015), there is a state vector $n \times 1$, which includes the value of $n$ concepts; and a $n \times n$ weight matrix $W$ (also known as adjacent matrix), that gets together all the weights $W_{i j}$ and the relationships between the $n$ criteria. Accordingly, the value of each concept is influenced by the values of its interconnected concepts and by its own previous value. This can be represented by formulation (1), where $A_{i}{ }^{(t+1)}$ is the activation level of concept C $i$ at time $t+1 ; f$ stands for a threshold activation function; $A_{i}^{(t)}$ represents the activation level of concept $C_{i}$ at time $t ; A_{j}{ }^{(t)}$ is the activation level of concept $C_{j}$ at time $t$; and $W_{j i}$ is the weight defined for the relationship between both concepts:

$$
A_{i}^{(t+1)}=f\left(A_{i}^{(t)}+\sum_{\substack{j \neq i \\ j=1}}^{n} A_{j}^{(t)} \cdot W_{j i}\right) .
$$

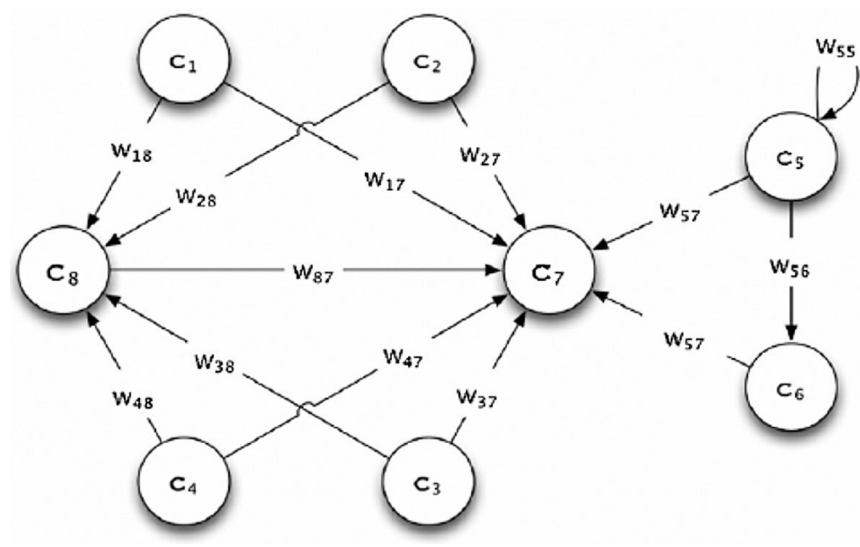

Fig. 1. Typical structure of an FCM Source: Salmeron (2012: 3706). 

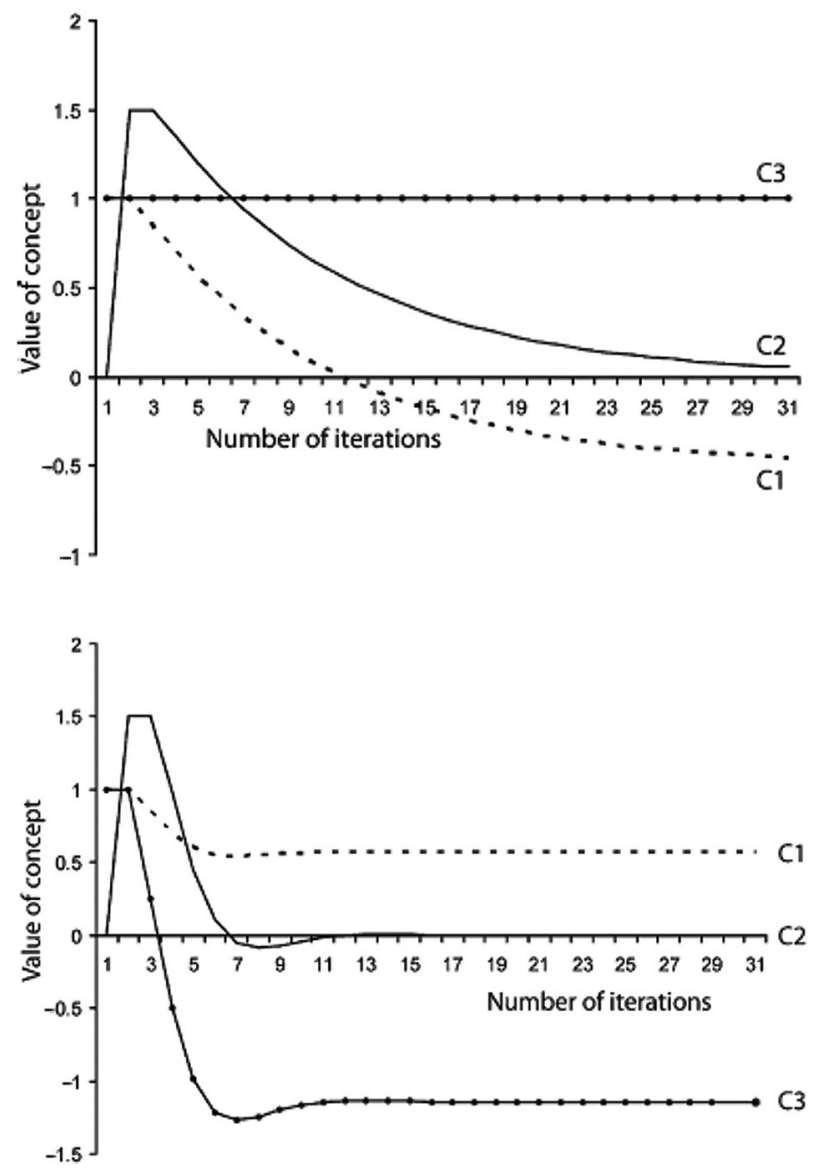

Fig. 2. FCM stabilization and value convergence points Source: Kok (2009: 125)

Following Carlucci et al. (2013: 213), "the resulting transformed vector is then repeatedly multiplied by the adjacency matrix and transformed until the system converges to a fixed point. Typically it converges in less than 30 simulation time steps". Figure 2 exemplifies this exercise based on a simulation carried out by Kok (2009).

In practice, the method is characterized as simple, flexible and supported on dynamic modeling, which allows complex decision problems to be converted into dynamic systems that evolve over time. Following Özesmi, U. and Özesmi, S. (2004), the FCM approach has the ability to: (1) allow for feedback analyses; (2) deal with many variables that may not be well defined; (3) model relationships between variables that are not known; (4) model systems where scientific information is limited, but where there are experts with knowledge about the decision problem; (5) reach similar results in comparison to other approaches, but with lower sample sizes; (6) combine different knowledge sources; and (7) increase the speed of the decision aid process. 
In terms of limitations, and in accordance with Schneider et al. (1998) and Özesmi, U. and Özesmi, S. (2004), decision-makers' ignorance and misconceptions are also coded in the maps. Additionally: (1) the problem can be modeled as FCM but this does not guarantee its resolution; (2) the map may not be able to model the occurrence of multiple causes; (3) the FCMs do not provide the actual value, but estimates of parameters or inferential statistical tests; and (4) FCMs are not clear as far as the concept of time is concerned. Other authors, such as Lee et al. (2013), also present the following limitations to FCMs: (i) when applied to the real world, FCMs are generally too large or complex; (ii) there are techniques for the construction of FCMs which are sometimes inadequate or impractical; (iii) existing efforts to deal with delays require the creation of fictitious nodes/criteria, artificially increasing the complexity of the map; and (iv) FCMs are non-linear systems. All in all, however, it is worth noting that FCMs have been acknowledged for holding "powerful and far-reaching consequences as a mathematical tool for modeling complex systems" (Mazlack 2009: 5).

\section{Model development}

\subsection{The structuring phase}

Many major decisions in organizations are made on a collective basis (Ferreira et al. 2012). In this sense, and because the facilitator (i.e. researcher) should "relate personally to a small number (say, three to ten persons)" (Eden, Ackermann 2001: 22), our study involved a group of seven residential real estate experts (i.e. 3 investors, 2 appraisers and 2 realtors), who operate in the metropolitan area of Lisbon. The housing market in Lisbon is similar to that in the rest of the country, and as such is characterized by strong access of families to property through credit; a relatively small rental market; a favouring of new construction at the expense of rehabilitation; and the strong importance of the construction sector and public works in the creation of wealth.

The experts included in our panel participated on a voluntary basis (i.e. after expressing interest in collaborating in the definition and analysis of our decision problem). Two group meetings with an average duration of 4.5 hours each were coordinated by two facilitators, assisted by an ICT technician, who was responsible for registering the meetings' outcomes.

The first group meeting started with a presentation of the study objectives and of the methodological procedures to be followed, allowing misunderstandings between the participants to be avoided. After this initial intervention, and in order to focus the panel members' attention on the problem at hand (i.e. risk assessment of residential real estate investments), the decision makers were asked the following trigger question: "Based on your values or professional experience, what are the main factors and/or characteristics of a house that influence its value and the associated risk of investment?". For clarification purposes, the concept of house was associated to single family apartment, because this is the most common type of residential real estate in the metropolitan area of Lisbon. In addition, the concept of risk was also clarified. In this context, this referred to the level of risk incurred by a purchaser when investing in real estate (in this case, a house); which in turn would result from the market value of that investment over time. This is why the trigger question focused on the determinants of house value, which in turn determine the associated risk of investment. 
Given these initial clarifications, the ensuing procedure consisted in the application of the "post-its technique" (Ackermann, Eden 2001), which "helps to identify clusters of linked aspects" (Bana e Costa et al. 2002: 229). During this phase of the process, the panel members were invited to share opinions, perceptions, experiences and values and, in sequence, to identify relevant criteria for the problem at hand, writing these criteria on post-its (i.e. one criterion per post-it). As expected, this allowed a wide range of different (but interrelated) criteria to be made explicit.

The second phase of the process consisted in grouping the criteria by "areas of concern" (i.e. clusters) and, subsequently, in the analysis of the cause-and-effect relationships between the criteria in each area of concern. The analysis of the cause-and-effect relationships was performed using the Decision Explorer software (http://www.banxia.com), which allowed a group map to be obtained. Figure 3 illustrates the final version of the collective map, which was discussed and validated by the expert panel.

The validated version of the collective map contained more than 150 concepts, and cannot be fully displayed in this paper (a full version can be obtained from the authors upon request). It should be highlighted, however, that its main contribution results from the insights brought to the process by the participating decision makers, as well as from the high amount of information analyzed and discussed regarding the cause-and-effect relationships between criteria. According to Carvalho (2013), the term "relationship" derives from the description of how the variables interact and are defined in a cognitive map. In this sense, the concept of fuzzy cause-and-effect relationships arises naturally, since it allows intermediate values of logical causality to be associated to the links.

Following this, the decision makers were asked to concentrate their attention on the cause-and-effect relationships between the criteria previously identified, and to define their respective degrees of intensity. The entire analysis was grounded on a saturated process of discussion and negotiation between the members of the expert panel, which included several

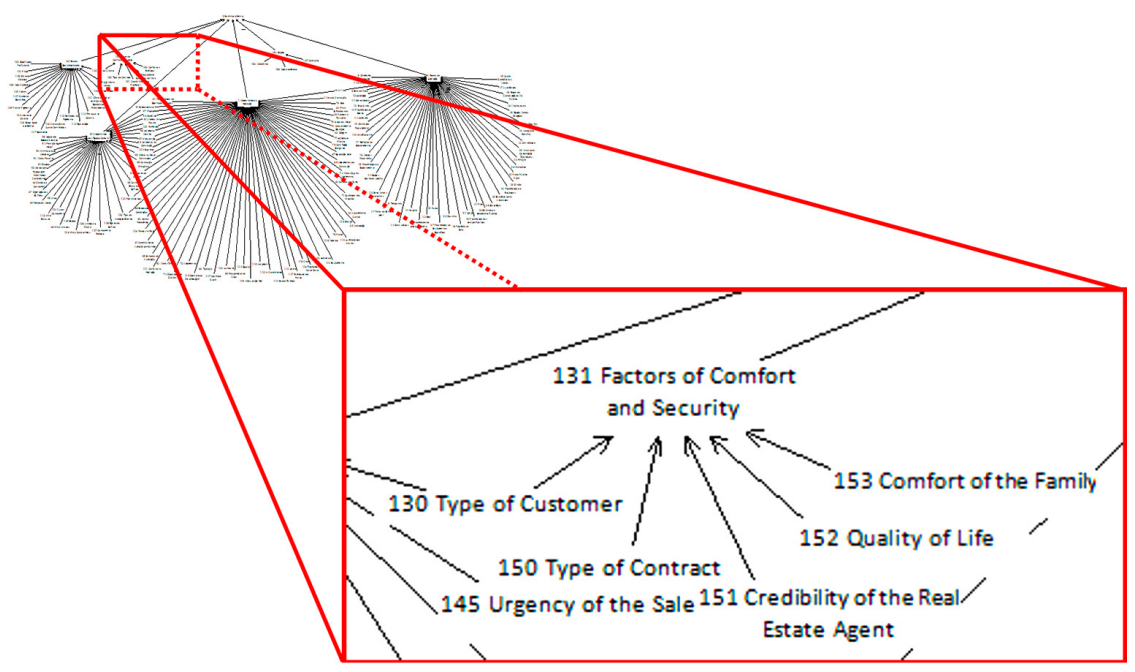

Fig. 3. Final version of the collective cognitive map 
logical analyses regarding risk assessment of residential real estate investments. The next step consisted in the introduction of the degrees of intensity in the cognitive structure, which was rebuilt using the FCMapper (http://www.fcmappers.net) and Panjek software (http://pajek. imfm.si/doku.php), allowing an FCM to be obtained. Resembling a neural network, Figure 4 illustrates the cognitive structure of the FCM, where the numbers represent the criteria identified in Figure 3 (a full version using concept names instead of numbers can be obtained from the authors upon request).

The panel members were provided with the cognitive structure illustrated in Figure 4. The ensuing discussion then allowed dynamic analyses to be performed, namely in terms of the impact that any fluctuation in the intensity levels between variables would have on the overall structure. This type of analysis was performed in all clusters, as exemplified in Figure 5, where the decimal values represent the degrees of intensity indicated and validated by the decision makers after negotiation.

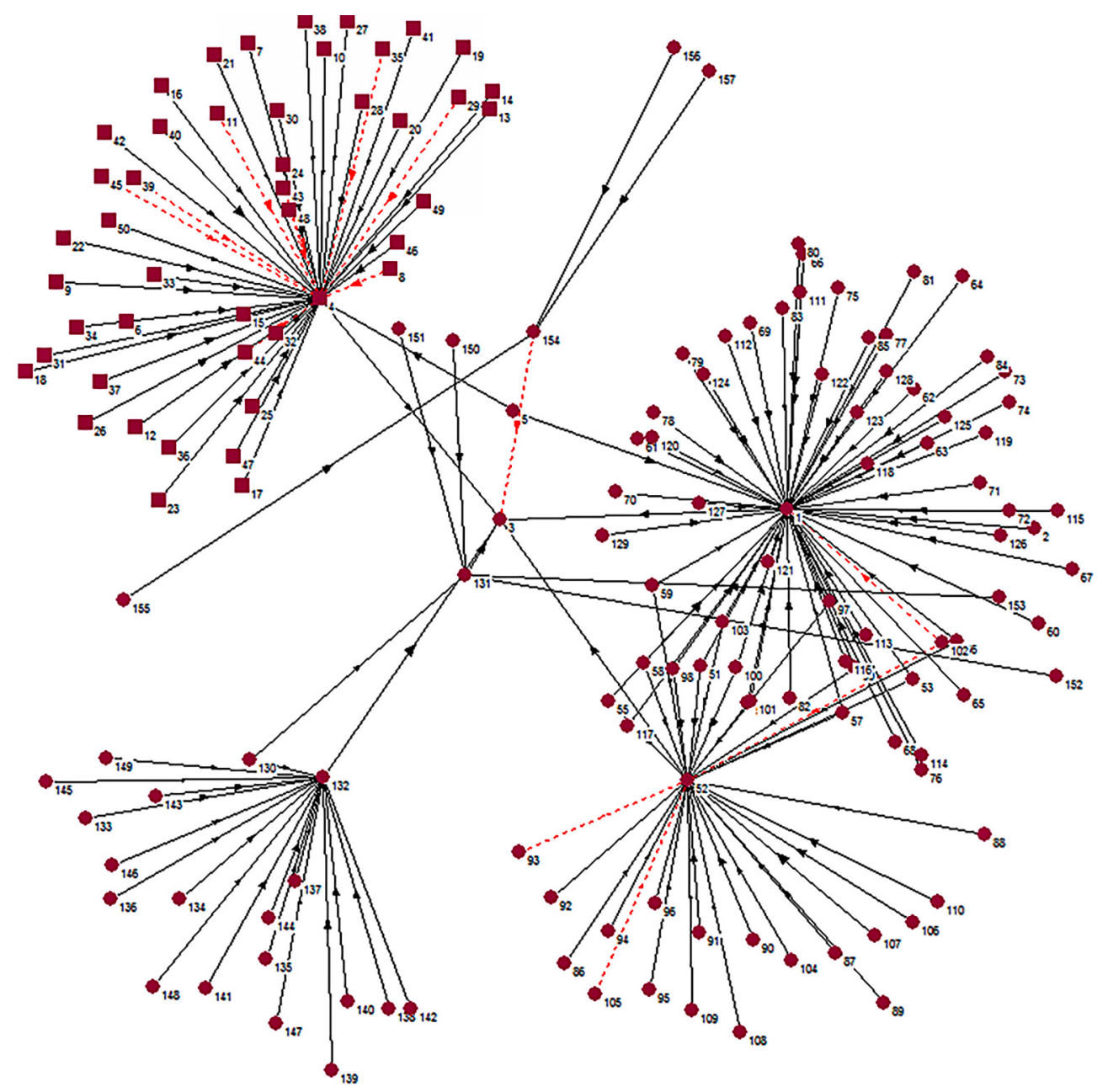

Fig. 4. Basic structure of the FCM 


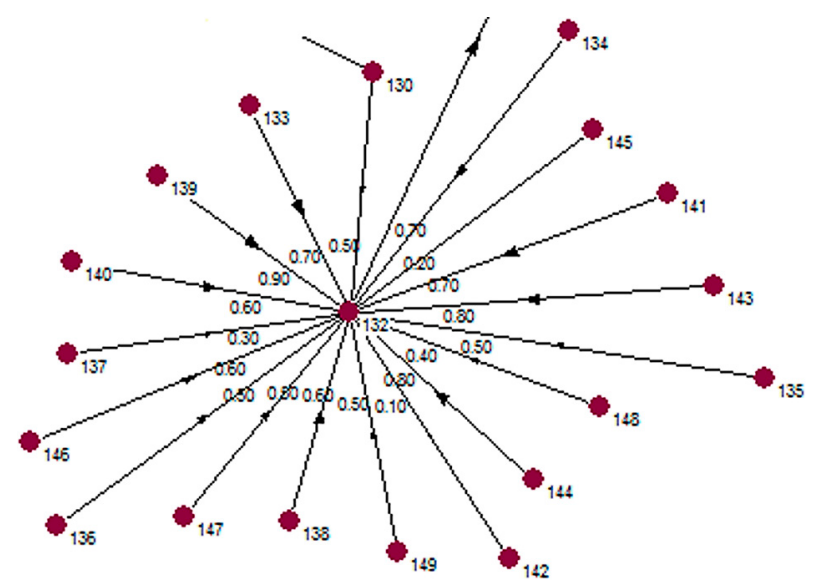

Fig. 5. Intensity degrees between criteria

From a learning perspective, the dynamic analysis carried out in this study, which is based on the use of fuzzy cognitive mapping techniques, was extremely important because it allowed the manner in which certain variables influence the risk of investment in residential real estate to be clarified. This benefit was explicitly highlighted by the group members. The conclusion of this phase of the session ended when, by consensus, the group validated the degrees of intensity defined. The next step consisted in analyzing the centrality of the determinants of investment risk included in the FCM.

\subsection{Centrality analysis on the determinants of investment risk}

Once the intensity values had been stabilized, it was possible to calculate a centrality level for each determinant of investment risk, and to conduct additional analyses to determine the consistency of the results. In practice, according to Carlucci et al. (2013: 216), "through a proper neural network computational model, [...] what we can get is an idea of the ranking of the variables in relationship to each other according to how the system is perceived in the FCM". Indeed, every single criterion identified in Figure 3 has a degree of centrality; and, because the development of an FCM allowed for the calculation of these degrees, it fostered an understanding of how the determinants of investment risk relate to each other, providing a knowledge base that can inform, for instance, the integrated application of an appraisal method or of a multiple criteria decision analysis (MCDA) technique to select the best investment alternative (for discussion and/or further details on the integrated use of these methodologies, see Zavadskas, Turskis 2011; Ferreira et al. 2012; Zavadskas et al. 2014).

Due to the large number of criteria validated by the panel members (i.e. more than 150), Table 1 reveals only the ones with the highest centrality indices. In practice, the results obtained here mean that when an investor intends to acquire a residential property, s/he is primarily focused on the housing characteristics (40.70), location (31.50), characteristics of the "common spaces" (16.90), social and economic factors (10.90), factors of comfort and security (4.40), stigmas (3.40) and construction/structure of the building (1.80). 
Table 1. Criteria with highest degrees of intensity (based on centrality)

\begin{tabular}{lcccc}
\hline \multicolumn{1}{c}{ Concept/Criterion } & Reference & Outdegree & Indegree & Centrality \\
\hline Housing characteristics & 1 & 0.80 & 39.90 & 40.70 \\
\hline Location & 4 & 0.70 & 30.80 & 31.50 \\
\hline Characteristics of the "Common Spaces" & 52 & 0.80 & 16.10 & 16.90 \\
\hline Social and economic factors & 132 & 1 & 9.90 & 10.90 \\
\hline Factors of comfort and security & 131 & 0.90 & 3.50 & 4.40 \\
\hline Stigmas & 154 & 0.80 & 2.60 & 3.40 \\
\hline Construction/structure of the building & 55 & 1.80 & 0.00 & 1.80 \\
\hline
\end{tabular}

Our findings using the FCM approach are consistent with the results of Cebula (2009) with regard to the importance of housing characteristics, in so far as this was the criterion identified by the experts displaying the highest level of centrality (this is also in accordance with the findings of Coulson, Leichenko 2001; Leichenko et al. 2001; Coulson, Lahr 2005; Laurice, Bhattacharya 2005; Sirmans et al. 2005; Ferreira et al. 2013b, who highlight the importance of (internal physical) housing characteristics in the assessment of housing value or investment). The FCM approach further identified a large number of other concepts or criteria, however; of which our focus was on the ones with the highest levels of centrality (see Table 1), and which are not, in our opinion, without consequence. The issue of stigma, for instance, is one that can be easily overlooked, but can at times affect the value of an investment over and above even housing characteristics. Indeed, as pointed out by one of the group members, some of the variables included in the FCM are rarely taken into consideration in current risk assessment practices, but the FCM allowed for their identification, reducing the rate of omitted criteria.

In addition to the ranking of variables provided, it should be noted that the major contribution of Table 1, as well as of the appraisal system itself, results from the ability to dynamically understand which variables support the calculation of each index. This allows information about the cause-and-effect relationships that support the analysis of risk assessment in residential real estate investments to be more structured and, as a result, can empower investment decisions. Furthermore, it was possible to identify some advantages of this approach, namely: the interactivity and dynamism of the techniques used and the fact that these techniques are extremely flexible and of simple application. Again, it was also noticed that the use of FCMs, despite its subjectivity, allows often omitted criteria to be contemplated in the modeling process, reinforcing the extant literature ( $c f$. Ferreira, Jalali 2015). Taking into account that the fuzzy evaluation model developed in this study is dynamic, it is also possible to understand the impact that any change in the variables considered can bring to the overall assessment of the risk of investment. Naturally, this study is not without limitations, which form the basis of our recommendations. 


\subsection{System validation, limitations and recommendations}

The cognitive structure developed in this study allows for greater transparency in the analysis of risk assessment in residential real estate, reinforcing the relevance of using FCMs in this domain. In addition, and as reported previously, the direct collaboration of a panel of experts proved to be valuable, providing realism, consistency and functionality to the system developed, which in turn allowed for its validation. It should be noted, however, that the greatest contribution of this study results, perhaps, from the learning process inherent to the use of FCMs, which, following a constructivist logic, allows reflections on risk assessments to take place and improvement suggestions to be formulated. As pointed out by Zavadskas and Turskis (2011: 398), "most importantly perhaps was the finding that decision analysis can be useful to help multiple stakeholders understand what they agree and disagree about, focus on the things that they disagree about and explore options that are better for everyone involved". Moreover, it is worth noting that, due to the constructivist nature of FCMs, our framework is flexible enough to accommodate new information, allowing real estate investors to immediately assess the impact of new criteria on the results. In this sense, it should be recalled that the proposal presented in this study is a work-in-progress, and improvements are always possible (and desirable) to strengthen real estate investment decisions.

\section{Conclusions}

Bearing in mind the importance of the housing sector to the socio-economic development of a country, the use of FCMs in this study allowed a comprehensive fuzzy model for risk assessment of residential real estate to be structured. This was an important achievement, given that the results obtained were consistent with the expert panel members' value judgments; and that the analysis of the cause-and-effect relationships between criteria allowed a new evaluation system for the assessment of residential real estate investment risk to be developed.

A major benefit of this evaluation system is that it enables a large number of determinants of risk assessment to be analyzed and structured. It also allows for greater transparency in the manner in which new information is integrated within it. This, in turn, allows for better informed and more comprehensive risk analysis decisions. In this sense, the application of FCMs to the real estate market (and investment risk analysis within it in particular), is not only of theoretical interest, in that it shows a new application of FCMs, and one which enables some of the previous limitations in real estate research to be overcome; but is also of practical interest, because it provides decision makers (in this case investors) with a tool for more informed decision making.

In its identification of determinants of real estate risk assessment, the framework developed not only confirmed some of the key variables previously referred to in the literature, but also highlighted a far greater number of variables, some markedly understudied, than is possible through traditional methods. In addition, the framework was endowed with added transparency and flexibility, insofar as there was transparency as to the source of the deter- 
minants, and the dynamic interactions between them are able to be mapped. While these results are in themselves of interest, an arguably more relevant contribution of this study is its illustration of the applicability of FCMs to the structuring and analysis of complex decision problems within the real estate industry. An applicability which, its limitations notwithstanding, has the advantage of being both replicable and dynamic.

In light of this reasoning, and although subjective in nature, the proposal presented in this study is above all a consolidated knowledge-based risk analysis framework for residential real estate investors. This is particularly important if we consider that "knowledge engineering is one of the most important tasks in developing expert systems. One of the primary objectives [...] is to develop a complete, consistent and unambiguous description of the knowledge base" (Kim, Lee 1998: 303). In this sense, our framework has an implicit strategic planning purpose, which consists in assisting decision makers to obtain important information about the impact of each determinant to support investment decisions in residential real estate. Although FCM managerial implications go far beyond the context of this study, we have found no previous documented evidence reporting the use this approach to identify key determinants of risk assessment in residential real estate.

Our results are encouraging but should be analyzed with caution, namely because the conception of an FCM is always context-dependent and, thus, subjective in nature. As already pointed out in the extant literature (cf. Carlucci et al. 2013; Ferreira, Jalali 2015), the context-dependence of an FCM structuring process results from the combination of several variables, such as: the decision circumstances, participating experts, facilitator skills and session duration. Still, it is more than compensated by the amount of information discussed and by the direct involvement of the experts in the decision making process.

As for future research, it is recommended to conduct similar analyses using other methodological approaches, such as MCDA, which offers a vast portfolio of techniques that allow trade-offs between criteria to be calculated (for further discussion and practical examples, see Belton, Stewart 2002; Zavadskas, Turskis 2011; Ferreira 2013; Ferreira et al. 2014; Zavadskas et al. 2014; Huguenin 2015). Another possibility may be to compare different methods and/or replicate the process followed in this study with a different set of decision-makers in order to receive another type of feedback and determine the robustness of the results. It is also noted the need to extend the methodological approach adopted in this study to other contexts, as well as the computerization of the model developed and/or its adaptation to online platforms in order to enable decision makers to evaluate, in a fast, transparent and intuitive manner, the risk of investment in residential real estate. Following this, any progress will be regarded as a breakthrough in supporting risk assessment of residential real estate investments.

\section{Acknowledgements}

The authors gratefully acknowledge the superb contribution and infinite willingness of the panel members: Amândio Rodrigues, António Augusto, Domingos Ribeiro, Helder Batista, Júlio Rainha, Paulo Vala and Rui da Nova. Institutional and facility support from the ISCTE Business School, University Institute of Lisbon, Portugal, is also acknowledged. 


\section{References}

Ackermann, F.; Eden, C. 2001. SODA - journey making and mapping in practice, in J. Rosenhead, J. Mingers (Eds.). Rational analysis for a problematic world revisited: problem structuring methods for complexity, uncertainty and conflict. $2^{\text {nd }}$ ed. John Wiley \& Sons, Chichester, 43-60.

Bana e Costa, C.; Corrêa, E.; De Corte, J.; Vansnick, J. 2002. Facilitating bid evaluation in public call for tenders: a socio-technical approach, Omega: The International Journal of Management Sciences 30(3): 227-242. https://doi.org/10.1016/s0305-0483(02)00029-4

Belton, V.; Stewart, T. 2002. Multiple criteria decision analysis: an integrated approach. Dordrecht, Kluwer Academic Publishers. https://doi.org/10.1007/978-1-4615-1495-4

Carlucci, D.; Schiuma, G.; Gavrilova, T.; Linzalone, R. 2013. A fuzzy cognitive map based approach to disclose value creation dynamics of ABIs, in $8^{\text {th }}$ International Forum on Knowledge Asset Dynamics (IFKAD-2013), 12-14 June, 2013, Zagreb, Croatia, 207-219.

Carvalho, J. 2013. On the semantics and the use of fuzzy cognitive maps and dynamic cognitive maps in social sciences, Fuzzy Sets and Systems 214: 6-19. https://doi.org/10.1016/j.fss.2011.12.009

Catalão, A. 2010. Estudo do Mercado Imobiliário de Aveiro [online], [cited 03 October 2014]. Available from Internet: http://hdl.handle.net/10773/3465

Cebula, R. 2009. The hedonic pricing model applied to the housing market of the city of Savannah and its Savannah historic landmark district, The Review of Regional Studies 39(1): 9-22.

Coulson, N.; Lahr, M. 2005. Gracing the land of Elvis and Beale street: historic designation and property values in Memphis, Real Estate Economics 33(3): 487-507.

https://doi.org/10.1111/j.1540-6229.2005.00127.x

Coulson, N.; Leichenko, R. 2001. The internal and external impact of historical designation on property values, Journal of Real Estate Finance and Economics 23(1): 113-124.

https://doi.org/10.1023/A:1011120908836

Doumpos, M.; Zopounidis, C. 2001. Assessing financial risks using a multicriteria sorting procedure: the case of country risk assessment, Omega: The International Journal of Management Sciences 29(1): 97-109. https://doi.org/10.1016/s0305-0483(00)00028-1

Ebru, C.; Eban, A. 2009. Determinants of house prices in Istanbul: a quantile regression approach, Quality \& Quantity 45(2): 305-317. https://doi.org/10.1007/s11135-009-9296-x

Eden, C. 2004. Analyzing cognitive maps to help structure issues or problems, European Journal of Operational Research 159(3): 673-686. https://doi.org/10.1016/S0377-2217(03)00431-4

Eden, C.; Ackermann, F. 2001. SODA - the principles, in J. Rosenhead, J. Mingers (Eds.). Rational analysis for a problematic world revisited: problem structuring methods for complexity, uncertainty and conflict. $2^{\text {nd }}$ ed. John Wiley \& Sons, Chichester, 21-41.

Eden, C.; Ackermann, F. 2004. Cognitive mapping expert views for policy analysis in the public sector, European Journal of Operational Research 152(3): 615-630.

https://doi.org/10.1016/S0377-2217(03)00061-4

Ferreira, F. 2013. Measuring trade-offs among criteria in a balanced scorecard framework: possible contributions from the multiple criteria decision analysis research field, Journal of Business Economics and Management 14(3): 433-447. https://doi.org/10.3846/16111699.2011.631744

Ferreira, F.; Jalali, M. 2015. Identifying key determinants of housing sales and time-on-the-market (TOM) using fuzzy cognitive mapping, International Journal of Strategic Property Management 19(3): 235-244. https://doi.org/10.3846/1648715X.2015.1052587

Ferreira, F.; Jalali, M.; Ferreira, J.; Stankevičienė, J.; Marques, C. 2016. Understanding the dynamics behind bank branch service quality in Portugal: pursuing a holistic view using fuzzy cognitive mapping, Service Business 10(3): 469-487. https://doi.org/10.1007/s11628-015-0278-x 
Ferreira, F.; Santos, S.; Rodrigues, P.; Spahr, R. 2014. Evaluating retail banking service quality and convenience with MCDA techniques: a case study at the bank branch level, Journal of Business Economics and Management 15(1): 1-21. https://doi.org/10.3846/16111699.2012.673504

Ferreira, F.; Spahr, R.; Gavancha, I.; Çipi, A. 2013a. Readjusting trade-offs among criteria in internal ratings of credit-scoring: an empirical essay of risk analysis in mortgage loans, Journal of Business Economics and Management 14(4): 715-740. https://doi.org/10.3846/16111699.2012.666999

Ferreira, F.; Spahr, R.; Santos, S.; Rodrigues, P. 2012. A multiple criteria framework to evaluate bank branch potential attractiveness, International Journal of Strategic Property Management 16(3): 254276. https://doi.org/10.3846/1648715X.2012.707629

Ferreira, F.; Spahr, R.; Sunderman, M. 2013b. Application of multiple criteria decision analysis (MCDA) in estimating residential real estate values, in $29^{\text {th }}$ Annual American Real Estate Society Meeting, 9-13 April, 2013, Kohala Coast, Hawaii, USA, 1-34.

Huguenin, J. 2015. Data envelopment analysis and non-discretionary inputs: how to select the most suitable model using multi-criteria decision analysis, Expert Systems with Applications 42(5): 25702581. https://doi.org/10.1016/j.eswa.2014.11.004

Jalali, M.; Ferreira, F.; Ferreira, J.; Meidute-Kavaliauskienè, I. 2016. Integrating metacognitive and psychometric decision making approaches for bank customer loyalty measurement, International Journal of Information Technology and Decision Making 15(4): 815-837. https://doi.org/10.1142/S0219622015500236

Kauko, T. 2010. Value stability in local real estate markets, International Journal of Strategic Property Management 14(3): 191-199. https://doi.org/10.3846/ijspm.2010.14

Keeney, R. 1996. Value-focused thinking: identifying decision opportunities and creating alternatives, European Journal of Operational Research 92(3): 537-549. https://doi.org/10.1016/0377-2217(96)00004-5

Kim, H.; Lee, K. 1998. Fuzzy implications of fuzzy cognitive map with emphasis on fuzzy causal relationship and fuzzy partially causal relationship, Fuzzy Sets and Systems 97(3): 303-313. https://doi.org/10.1016/S0165-0114(96)00349-1

Kok, K. 2009. The potential of fuzzy cognitive maps for semi-quantitative scenario development, with an example from Brazil, Global Environmental Change 19(1): 122-133. https://doi.org/10.1016/j.gloenvcha.2008.08.003

Kosko, B. 1986. Fuzzy cognitive maps, International Journal of Man-Machine Studies 24(1): 65-75. https://doi.org/10.1016/S0020-7373(86)80040-2

Laurice, J.; Bhattacharya, R. 2005. Prediction performance of a hedonic pricing model for housing, Appraisal Journal, 73(2): 198-209.

Lee, K.; Lee, H.; Lee, N.; Lim, J. 2013. An agent-based fuzzy cognitive map approach to the strategic marketing planning for industrial firms, Industrial Marketing Management 42(4): 552-563. https://doi.org/10.1016/j.indmarman.2013.03.007

Leichenko, R.; Coulson, N.; Listokin, D. 2001. Historic preservation and residential property values: an analysis of Texas cities, Urban Studies 38(11): 1973-1987. https://doi.org/10.1080/00420980120080880

Lopez, J.; Saidenberg, M. 2000. Evaluating credit risk models, Journal of Banking \& Finance 24(1): 151-165. https://doi.org/10.1016/S0378-4266(99)00055-2

Mazlack, L. 2009. Representing causality using fuzzy cognitive maps, in Annual Meeting of the North American Fuzzy Information Processing Society (NAFIPS-2009), 14-17 June, 2009, Cincinnati, Ohio, USA, 1-6. https://doi.org/10.1109/nafips.2009.5156434

Montibeller, G.; Belton, V. 2006. Causal maps and the evaluation of decision options: a review, Journal of the Operational Research Society 57(7): 779-791.

https://doi.org/10.1057/palgrave.jors.2602214 
Onofrei, M.; Anghel, I. 2012. Risks and rewards of leverage in Romanian real estate investment, Procedia - Economics and Finance 3: 481-488.

Özesmi, U.; Özesmi, S. 2004. Ecological models based on people’s knowledge: a multi-step fuzzy cognitive mapping approach, Ecological Modelling 176: 43-64. https://doi.org/10.1016/j.ecolmodel.2003.10.027

Rybak, J.; Shapoval, V. 2011. Industries and sectors: issues and policies, tendencies of real estate market development in the current context (in terms of Poland and Ukraine), Perspectives of Innovations, Economics \& Business 8(2): 17-22.

Salmeron, J. 2012. Fuzzy cognitive maps for artificial emotions forecasting, Applied Soft Computing 12(12): 3704-3710. https://doi.org/10.1016/j.asoc.2012.01.015

Santos, S.; Belton, V.; Howick, S. 2002. Adding value to performance measurement by using system dynamics and multicriteria analysis, International Journal of Operations \& Production Management 22(11): 1246-1272. https://doi.org/10.1108/01443570210450284

Schneider, M.; Shnaider, E.; Kandel, A.; Chew, G. 1998. Automatic construction of FCMs, Fuzzy Sets and Systems 93(2): 161-172. https://doi.org/10.1016/S0165-0114(96)00218-7

Sirmans, S.; Macpherson, D.; Zeitz, E. 2005. The composition of hedonic pricing models, Journal of Real Estate Literature, 13(1): 3-43.

Steiger, D.; Steiger, N. 2008. Instance-based cognitive mapping: a process for discovering a knowledge worker's tacit mental model, Knowledge Management Research \& Practice 6(4): 312-321. https://doi.org/10.1057/kmrp.2008.19

Šušteršic, M.; Mramor, D.; Zupan, J. 2009. Consumer credit scoring models with limited data, Expert Systems with Applications 36(3): 4736-4744. https://doi.org/10.1016/j.eswa.2008.06.016

Syz, J.; Vanini, P.; Salvi, M. 2008. Property derivatives and index-linked mortgages, Journal of Real Estate Finance and Economics 36(1): 23-35. https://doi.org/10.1007/s11146-007-9071-5

Tavares, F.; Pereira, E.; Moreira, A. 2009. Avaliação imobiliária pelo método comparativo na óptica do avaliador, Economia Global e Gestão 14(3): 111-128.

Tegarden, D.; Sheetz, S. 2003. Group cognitive mapping: a methodology and system for capturing and evaluating managerial and organizational cognition, Omega: The International Journal of Management Sciences 31(2): 113-125. https://doi.org/10.1016/s0305-0483(03)00018-5

Wang, G.; Hao, J.; Ma, J.; Jiang, H. 2011. A comparative assessment of ensemble learning for credit scoring, Expert Systems with Applications 38(1): 223-230. https://doi.org/10.1016/j.eswa.2010.06.048

Warren, A. 2011. Global Real Estate Trends: Canada's Real Estate Market Slows While Most International Markets Stumble. Global Economic Research.

Wenpo, Y.; Minli, Z. 2012. Fuzzy comprehensive evaluation method applied in the real estate investment risks research, Physics Procedia 24: 1815-1821. https://doi.org/10.1016/j.phpro.2012.02.267

Yancang, L.; Juanjuan, S. 2009. Model on risk evaluation of real estate investment, in Y. Chen, H. Deng, D. Zhang, Y. Wiao (Eds.). Sixth international conference on fuzzy systems and knowledge discovery Vol. 3. IEEE Computer Society, 138-140. https://doi.org/10.1109/FSKD.2009.60

Zavadskas, E.; Turskis, Z. 2011. Multiple criteria decision making (MCDM) methods in economics: an overview, Technological and Economic Development of Economy 17(2): 397-427. https://doi.org/10.3846/20294913.2011.593291

Zavadskas, E.; Turskis, Z.; Kildiene, S. 2014. State of art surveys of overviews on MCDM/MADM methods, Technological and Economic Development of the Economy 20(1): 165-179.

https://doi.org/10.3846/20294913.2014.892037 
Mónica I. F. RIBEIRO works in the private sector, where she provides audit, tax and advisory services to help national and international companies and organizations negotiate risks and thrive in the varied environments in which they do business. Her research interests include finance, accounting and decision support systems (DSS).

Fernando A. F. FERREIRA is Assistant Professor and Vice-Dean for financial affairs at the ISCTE Business School of the University Institute of Lisbon, Portugal, and Adjunct Research Professor at the Fogelman College of Business and Economics of the University of Memphis, TN, USA. He holds a $\mathrm{PhD}$ in Quantitative Methods Applied to Economics and Management from the University of Algarve, Portugal. Some of his articles are published by ISI-listed journals such as Journal of the Operational Research Society, Management Decision, Journal of Business Research, and International Journal of Strategic Property Management. He has practical experience as group facilitator and his research interests include multiple criteria decision analysis, fuzzy logics and integrated systems for performance measurement.

Marjan S. JALALI is Assistant Professor at the ISCTE Business School of the University Institute of Lisbon, and researcher at the Business Research Unit (BRU-IUL), Portugal. She holds a PhD in Management from the University of Sydney, Australia. She is editorial board member of the Global Business and Economics Review, managing editor of the International Journal of Management Science and Information Technology, and some of her works have been published nationally and internationally. Her research interests include multiple criteria decision analysis, strategic decision making and consumer behavior.

Ieva MEIDUTE்-KAVALIAUSKIENE் is Associate Professor and Vice-Dean at the Faculty of Business Management of the Vilnius Gediminas Technical University, Lithuania. She holds a PhD in Technological Science from the Vilnius Gediminas Technical University. She has authored peer-reviewed papers and some of her works have been presented and published nationally and internationally. She is editorial board member of several international journals and her research interests include decision analysis and operations management. 